\title{
O DIREITO À EDUCAÇÃO DE QUALIDADE NO MERCOSUL
}

\author{
EL DERECHO A LA EDUCACIÓN DE CALIDAD EM EL MERCOSUR
}

THE RIGHT TO QUALITY EDUCATION IN MERCOSUR

\author{
Kellcia Rezende SOUZA ${ }^{1}$ \\ Maria Teresa Miceli KERBAUY ${ }^{2}$
}

RESUMO: O objetivo da pesquisa consiste em analisar o direito à educação a partir dos indicadores de qualidade educacional nos países do Mercosul (Argentina, Brasil, Paraguai, Uruguai e Venezuela). Trata-se de um dos resultados mensurados pela Tese de Doutorado intitulada "O Direito à educação nos países membros do Mercosul: um estudo comparado". A fim de propiciar o alcance do objetivo proposto foi realizada uma pesquisa bibliográfica e documental com enfoque qualitativo. A fonte documental se constituiu pelos relatórios do Programa das Nações Unidas para o Desenvolvimento (PNUD), tendo como categorias de análise a despesa pública destinada a educação e o índice de qualidade de ensino dos membros do bloco. Ademais, a discussão versou pela comparação e confronto dos dados dos indicadores educacionais dos Estados membros do Mercosul com a literatura da área. Apesar dos países do bloco apresentarem, nas últimas décadas, a expansão de investimentos e, também, da cobertura de vagas para a educação básica, esse crescimento não esteve atrelado a qualidade, com exceção de Argentina e o Uruguai, que são os países com os mais elevados indicadores educacionais e figuram entre os melhores colocados, se compararmos igualmente os demais países da América Latina. Esse quadro se apresenta como um entrave não só para o desenvolvimento social, político e econômico dos países, como, também, para a consolidação de um processo efetivo de integração regional no âmbito Mercosul.

PALAVRAS-CHAVE: Direito à educação. Mercosul. Política educacional.

RESUMEN: El objetivo de la investigación consiste en analizar el derecho a la educación a partir de los indicadores de calidad educativa en los países del Mercosur (Argentina, Brasil, Paraguay, Uruguay y Venezuela). Se trata de uno de los resultados medidos de la Tesis de Doctorado titulada "El derecho a la educación en los países miembros del Mercosur: un estudio comparado". Con el fin de propiciar el alcance del objetivo propuesto se realizó una investigación bibliográfica y documental con enfoque cualitativo. La fuente documental se constituyó por los informes del Programa de las Naciones Unidas para el Desarrollo (PNUD), teniendo como categorías de análisis el gasto público destinado a la educación y el índice de calidad de enseñanza de los miembros del bloque. Además, la discusión versó por la comparación y confrontación de los datos de los indicadores educativos de los Estados miembros del Mercosur con

${ }^{1}$ Universidade Federal da Grande Dourados (UFGD), Dourados - MS- Brasil. Professora Doutora da Faculdade de Educação. E-mail: kellciasouza@ufgd.edu.br.

${ }^{2}$ Universidade Estadual Paulista (UNESP), Araraquara - SP - Brasil. Professora Doutora do Programa de Pós-Graduação em Educação Escolar. E-mail: kerbauy@ travelnet.com.br.

RIAEE - Revista Ibero-Americana de Estudos em Educação, Araraquara, v.12, n.4, p.2245-2260, out./dez. 2017. 
la literatura del área. A pesar de que los países del bloque presentaron, en las últimas décadas, la expansión de inversiones y, también, de la cobertura de vacantes para la educación básica, ese crecimiento no estuvo ligado a la calidad, con excepción de Argentina y Uruguay, que son los países con los países más altos indicadores educativos y figuran entre los mejores colocados, si comparamos igualmente los demás países de América Latina. Este cuadro se presenta como un obstáculo no sólo para el desarrollo social, político y económico de los países, sino también para la consolidación de un proceso efectivo de integración regional en el ámbito Mercosur.

PALAVRAS-CLAVE: Derecho a la educación. Mercosur. Política educativa.

ABSTRACT: The objective of the research is to analyze the right to education based on indicators of educational quality in the Mercosur countries (Argentina, Brazil, Paraguay, Uruguay and Venezuela). This is one of the measured results of the Doctoral Thesis titled "The Right to Education in Mercosur member countries: a comparative study". In order to facilitate the achievement of the proposed objective, a qualitative bibliographical and documentary research was carried out. The documentary source consisted of the reports of the United Nations Development Program (UNDP), analyzing the public expenditure on education and the quality index of education of the members of the bloc. In addition, the discussion was based on the comparison and comparison of the data of the educational indicators of the Mercosur member states with the literature of the area. In spite of the fact that the countries of the bloc have in the last decades shown the expansion of investments and also the coverage of vacancies for basic education, this growth was not linked to quality, with the exception of Argentina and Uruguay, which are the countries with the educational indicators and are among the best placed, if we compare the other Latin American countries as well. This framework presents itself as an obstacle not only to the social, political and economic development of the countries, but also to the consolidation of an effective process of regional integration within Mercosur.

KEYWORDS: Right to education. Mercosur. Educational politics.

\section{Introdução}

O avanço do processo de globalização desencadeou novas formas de relações multilaterais, em que a formação de blocos regionais tornou-se crucial para a integração econômica, política, social e cultural, como uma importante estratégia de inserção no cenário internacional. A celebração de aparatos normativos está intimamente relacionada à relação de estreitamento estabelecida entre os Estados.

Nesse sentido, a constituição dos blocos regionais também passou a ser decisiva nos mecanismos de pactuar compromissos a partir de atos normativos celebrados no âmbito internacional, em especial, no campo da proteção aos direitos. Sendo assim, os processos de integração regionais, desse modo, operam transformações não só no

RIAEE - Revista Ibero-Americana de Estudos em Educação, Araraquara, v.12, n.4, p.2245-2260, out./dez. 2017. 
cenário internacional, mas, sobretudo, no contexto dos países envolvidos, na medida em que envolvem procedimentos de convergências, aproximações e harmonizações de políticas e normatizações. Logo, os blocos regionais ganham espaço não só na vertente econômica, mas, na política e no campo social, pois a condição de regionalização passa a representar uma estrutura mais sólida para responder aos anseios advindos das constantes mudanças do mundo globalizado.

O Mercosul foi criado nesse contexto, pelo Tratado de Assunção em 1991, com o objetivo de promover a livre circulação de bens, serviços e capitais entre os países do Cone Sul - Argentina, Brasil, Paraguai e Uruguai ${ }^{3}$, por meio da eliminação dos direitos alfandegários e restrições não tarifárias de mercadorias. Trata-se de um pacto regional para o fortalecimento econômico dos respectivos países (PILETTI; PRAXEDES, 1998). Em 2012, a Venezuela ingressou como quinto país membro do bloco.

Embora o Mercosul seja um acordo que abarca eminentemente o setor econômico e comercial, incorpora, desde o início, outros setores que possuem estrita relação com o desenvolvimento político, econômico e social dos Estados que o integram, dentre eles, a educação. Denota-se, portanto, que o ingresso da educação na agenda do Mercosul demonstra uma diversificação na pauta do bloco, que foi criado com a finalidade de fortalecer a economia regional.

Nesse viés, o presente tem como objetivo analisar o direito à educação a partir de indicadores de qualidade educacional nos países do Mercosul (Argentina, Brasil, Paraguai, Uruguai e Venezuela). A fim de propiciar o alcance do objetivo proposto foi realizada uma pesquisa bibliográfica e documental com enfoque qualitativo. A fonte documental se constituiu pelos relatórios do Programa das Nações Unidas para o Desenvolvimento (PNUD) do período de 2005 à 2015, tendo como categorias de análise a despesa pública destinada a educação e o índice de qualidade de ensino dos membros do bloco.

Assim sendo, o presente estudo busca contribuir para o fortalecimento de um campo de investigação - ainda em processo tímido de consolidação - referente às ações organizadas pelo Mercosul Educacional, no qual estão inseridas análises concernentes à implantação de políticas educacionais de proporção internacional, visando a garantia do direito à educação. Trata-se, portanto, de trazer as políticas públicas educacionais no

${ }^{3} \mathrm{O}$ recorte do estudo delimita apenas os países pertencentes ao Mercosul. Dessa forma, não atentaremos à discussão dos Estados Associados - Chile, Bolívia, Colômbia, Equador e Peru, assim como os demais países latino-americanos, cuja realidade econômica, social e, dentro desta, educacional, apresenta muitos traços de similaridade (BABINSKI, 2010).

RIAEE - Revista Ibero-Americana de Estudos em Educação, Araraquara, v.12, n.4, p.2245-2260, out./dez. 2017. 
âmbito internacional, em especial da América do Sul, para o centro da cena dos debates educacionais, em particular aqueles voltados para os "[...] direitos sociais e para a premência de seu resgate e usufruto para e pela maioria da população" (SANTOS; AZEVEDO, 2009, p. 534).

\section{Qualidade educacional no Mercosul}

No âmbito das diretrizes internacionais foram pactuados, nas últimas duas décadas (1990 e 2000), compromissos assumidos por diferentes países, objetivando assegurar o direito educacional, tendo a qualidade como finalidade para a elaboração de políticas públicas. Os debates, nesse contexto, têm se pautado no entendimento de que o direito à educação não abrange somente o acesso e a permanência ${ }^{4}$, mas a garantia de um padrão de qualidade como um dos princípios para a sua efetivação (VIEIRA, 2014).

A questão da qualidade na educação é uma pauta mundial que foi, conforme Oliveira e Araújo (2005, p. 8), progressivamente, se tornando central no debate internacional da área e os governantes intensificaram em vários países, inclusive os da América Latina, um processo significativo de ampliação das oportunidades de escolarização da população. "Foram incorporadas parcelas da população que antes não tinham acesso à educação e cujas experiências culturais eram diferentes daqueles que antes constituíam o grupo de usuários da escola". Isso acarretou tensionamento de questões que ultrapassam o aspecto quantitativo da expansão do acesso, pois as contradições e as diferenças sociais, que são históricas na região, passaram a estar presentes, também, no contexto escolar.

Dessa maneira, a qualidade educacional, conforme Cabral e Di Giorgi (2012), passou a ser direcionada no debate sobre a educação escolar formal a partir da perspectiva da aprendizagem mais efetiva, que envolve, inclusive, relações sociais amplas. Assim, com as atuais demandas referentes à percepção de qualidade do ensino e a relevância da educação escolar, a avaliação em larga escala e, consequentemente, seus

4 "Desse modo, até a década de 1980, as buscas da sociedade pelo acesso à escola e a todos os bens sociais e econômicos que as oportunidades educacionais oferecem, bem como a satisfação dessas demandas pelo poder público, caracterizaram a ampliação quantitativa da escolarização. Sendo uma das metas principais dos governos referente à educação, acesso e permanência na escola. A demanda pela ampliação de vagas era muito mais forte do que a reflexão sobre a forma que deveria assumir o processo educativo e as condições necessárias para a oferta de um ensino de qualidade. Foi a incorporação quase completa de todos à etapa obrigatória de escolarização que fez emergir o problema da qualidade em uma configuração inteiramente nova" (VIEIRA, 2014, p. 9).

RIAEE - Revista Ibero-Americana de Estudos em Educação, Araraquara, v.12, n.4, p.2245-2260, out./dez. 2017. 
indicadores, tornaram-se instrumentos cada vez mais usados na definição das políticas públicas para a área em vários países do mundo.

Minayo (2009) esclarece que os indicadores resultantes das avaliações de larga escala assinalam tendências. Assim sendo, nenhum indicador pode apontar uma certeza absoluta quanto aos resultados de uma ação ou de um processo, pois sua função é limitada a ser um sinalizador. Os indicadores, por sua vez, são instrumentos, não operam por si mesmos, mas indicam cenários dos fenômenos investigadas.

Quando observados do ponto de vista quantitativo e qualitativo, os indicadores se referem aos aspectos tangíveis e intangíveis da realidade. Tangíveis são os elementos facilmente observáveis, como renda, escolaridade, forma de organização e gestão, legislação, mecanismos de divulgação. Intangíveis são os atributos que só podem ser captados indiretamente por meio de suas formas de manifestação, como é o caso do incremento da consciência social, da autoestima, de valores, de atitudes, de liderança, de protagonismo e de cidadania. Como essas são dimensões complexas da realidade, processos nãolineares ou progressivos, demandam um conjunto de indicadores que apreendam algumas de suas manifestações indiretas, cercando a complexidade do que pretendemos observar. (MINAYO, 2009, p. 85)

Diante do exposto e para a investigação proposta, tomamos como unidade de análise alguns dos indicadores educacionais que balizaram a avaliação do desenvolvimento humano dos países do Mercosul e que foram divulgados no relatório de 2005 e 2015 do Programa das Nações Unidas para o Desenvolvimento: despesa pública com a educação e o índice de qualidade de ensino. Essa avaliação consiste em um instrumento que reúne, anualmente, indicadores comparativos do panorama social e econômico dos países e tem servido como parâmetro para a formulação de diretrizes de ações pela comunidade internacional, bem como, para a formulação, reformulação e o monitoramento das políticas públicas educacionais e, principalmente, dos ordenamentos legais no âmbito dos Estados.

Em que pese a consolidação do direito à educação não só mediante a cobertura nos dispositivos constitucionais e legais dos países do Mercosul, é necessário a análise da materialização deste direito na realidade social considerando os indicadores educacionais, uma vez que o direito educacional nos países do bloco apresentam pontos semelhantes e aspectos que se diferenciam, o que imprime a demanda de compreender a aplicabilidade das normativas legais no meio social.

Quanto ao orçamento destinado à educação, a Tabela 1 nos mostra que a Venezuela é o país que mais investe no setor educacional, o que corresponde a 6,9\% do

RIAEE - Revista Ibero-Americana de Estudos em Educação, Araraquara, v.12, n.4, p.2245-2260, out./dez. 2017. 
seu Produto Interno Bruto (PIB). Na sequência estão Brasil (5,8\%), Argentina (5,1\%), Paraguai $(5,0 \%)$. Por fim, o país com a menor despesa pública em educação é o Uruguai $(4,4 \%)$

Tabela 1: Despesa pública com educação nos países do Mercosul

\begin{tabular}{lc}
\hline \multicolumn{1}{c|}{ PAÍSES } & Percentual do PIB \\
\hline Argentina & $5,1 \%$ \\
Brasil & $5,8 \%$ \\
Paraguai & $5,0 \%$ \\
Uruguai & $4,4 \%$ \\
Venezuela & $6,9 \%$ \\
\hline Média investida do PIB dos países do & $5,4 \%$ \\
Mercosul* & \\
\hline
\end{tabular}

* Cálculo realizado pela pesquisadora.

Fonte: Elaboração própria a partir dos dados do Relatório do Programa das Nações Unidas para o Desenvolvimento (PNUD, 2015).

O único país do bloco que fixa um percentual do PIB para destinar à educação é a Argentina. A sua Lei de Educação Nacional n. 26.206/2006 determina que 6\% do PIB devem ser investidos na área educacional. Contudo, como podemos aferir pelos dados do PNUD, mesmo com a previsão legal de um percentual, o país ainda não concretiza essa normativa. A Venezuela, mesmo não apresentando a fixação de percentuais do PIB em sua legislação, mais que dobrou o investimento em educação, como podemos notar pelo Gráfico 1, que traz os dados do Relatório de 2005.

Gráfico 1: Despesa pública com a educação (Percentual do PIB 2005 e 2015)

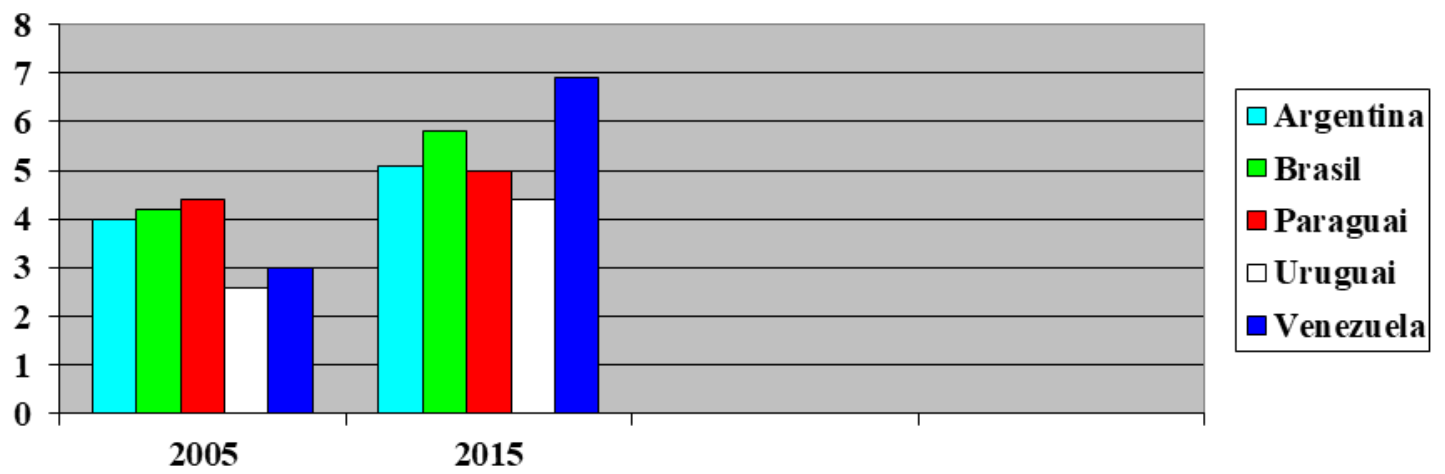

Fonte: Elaboração própria a partir dos dados do Relatório do Programa das Nações Unidas para o Desenvolvimento (PNUD, 2005 e 2015).

Mesmo que a Argentina não tenha alcançado o patamar de 6\% do seu PIB, Susmel (2014) destaca que nos últimos anos, os gastos do Estado com a educação no país têm aumentado. No entanto, o autor ressalta que, devido às assimetrias regionais no país, há uma

RIAEE - Revista Ibero-Americana de Estudos em Educação, Araraquara, v.12, n.4, p.2245-2260, out./dez. 2017. 
disparidade representada pelo investimento em educação por aluno entre as províncias, o que reflete na qualidade. Há províncias que investem até três vezes mais do que a média estatal, diferente de outras, em que o montante destinado à educação é inferior ao aporte do governo federal.

A Argentina, segundo Relatório do Programa das Nações Unidas para o Desenvolvimento de 2005, destinava 4,0\% do PIB, o Brasil, 4,2\%, Paraguai, 4,4\%, Uruguai, 2,6\% e Venezuela, 3,0\%. O Gráfico 1 ilustra a ampliação de investimentos em todos os países. Notamos que a Venezuela mais que dobrou o orçamento destinado à educação e na mesma direção, está o Uruguai. Argentina e Brasil sinalizaram um crescimento dos recursos de forma mais tímida, comparando-se aos anos anteriores. O Paraguai foi o país que apresentou o menor nível de crescimento do investimento do PIB.

Logo, notamos que a Venezuela ampliou o crescimento em 3,9\% nos períodos compreendidos da disponibilização dos dados dos relatórios, Argentina, 1,1\%, Brasil, 1,6\%, Paraguai, $0,6 \%$ e Uruguai, $1,8 \%$. O Uruguai, mesmo sendo o país que investe a menor proporção do PIB comparado aos demais, quase dobrou a soma que era destinada em 2005, o que representa um crescimento expressivo, principalmente se levarmos em conta que o país não possui nenhuma referência legislativa que determine percentuais de investimentos em educação. Para Babinski (2010), ainda que o Uruguai tenha ampliado os investimentos em educação na última década de forma significativa, a falta da previsão legal para fixar patamares de investimento é uma grave falha na legislação uruguaia, bem como deixa o país à mercê das prioridades de determinado governo e não configura um compromisso do Estado.

No entender de Akkari e Nogueira (2007), é preciso considerar que há uma tensão constante entre a quantidade e a qualidade, que um não é sinônimo de outro e vice-versa. Ambos os processos devem ser equilibrados para que o sistema de ensino consiga alcançar patamares positivos. A ampliação da cobertura deve vir acompanhada da priorização de investimentos em formação de profissionais, infraestrutura, materiais pedagógicos, bem como de uma redefinição de processos avaliativos, curriculares e de gestão.

Em outras palavras, a oferta leva tempo para se materializar, enquanto a demanda é imediata. Se não há essa compreensão por parte do Estado, a quantidade de recursos dedicados à educação não representará necessariamente a garantia de êxito, se não houver um planejamento que contemple as políticas educacionais de longo prazo.

Akkari e Nogueira (2007) chamam a atenção para o fato de que o Brasil tem um nível de desenvolvimento educacional muito abaixo da sua posição econômica. O país, 
por exemplo, investe percentuais do PIB próximos aos do Paraguai, país que tem uma economia inferior à de muitos países latino-americanos. Por conta desse cenário, inúmeros movimentos sociais no país reivindicam, como condição crucial para a melhoria da qualidade e, também, da ampliação da cobertura, sobretudo para Educação Infantil, o aumento dos recursos destinados à educação no país.

O Brasil projeta a ampliação de investimentos na área a partir da Lei $n$. 13.005/2014, que determinou seu Plano Nacional de Educação (2014-2024) e regulamentou como meta a aplicação de recursos públicos em educação como proporção do PIB ao patamar de $7 \%$ do PIB até o quinto ano de vigência da referida lei e, no mínimo, o equivalente a $10 \%$ do PIB ao final do decênio. Ao analisarmos o crescimento entre os dados apresentados no relatório de 2005 (4,2\%) e os apresentados em 2015 (5,8\%), evidenciamos que o aumento foi de 1,6\%, o que demonstra o crescimento de 0,8\% a cada quinquênio. Essa observação demonstra que a projeção de elevação do PIB ao patamar de $10 \%$ no país se constitui em um grande desafio, o que exigirá dos governos a priorização das políticas educacionais.

Quanto à América Latina, Akkari e Nogueira (2007, p. 136) advertem para as desigualdades flagrantes na redistribuição da riqueza, que reflete, por sua vez, nas desigualdades ao acesso educacional. Se considerarmos o nível de desenvolvimento econômico dos países da América Latina, constatamos que as crianças pobres tendem a frequentar sistemas de educação pública deteriorados. O serviço educacional limitado na América Latina agrava as desigualdades e coloca em alerta as políticas educacionais vigentes, sobretudo as referentes "[...] aos problemas da qualidade da educação, de insuficiência de fundos, da distribuição inadequada dos recursos e das péssimas condições de trabalho dos educadores são temas que precisam ser melhor estudados na região" e, principalmente, priorizados na definição de políticas públicas para área.

Dourado e Oliveira (2009) ressaltam que o financiamento público é fundamental para o estabelecimento de condições objetivas para a oferta de educação de qualidade e para a implementação de políticas públicas que objetivem ampliar a cobertura dessa oferta, o que demandará o compromisso dos países com os diferentes níveis, etapas e modalidades educacionais.

A Unesco compreende os recursos financeiros como uma das dimensões que incidem na qualidade educacional. Para o órgão, do ponto de vista econômico, é qualitativo afirmar que a qualidade está relacionada à eficiência no uso do orçamento destinado à educação (UNESCO, 2013). Considerando essa percepção e a partir dos dados referentes aos

RIAEE - Revista Ibero-Americana de Estudos em Educação, Araraquara, v.12, n.4, p.2245-2260, out./dez. 2017. 
indicadores da educação Uruguaia, é possível afirmar que, mesmo dispondo de um percentual menor de recursos, comparado aos demais, tem alcançado resultados consideráveis na esfera educacional.

Nessa direção, mesmo com o menor índice de investimento em educação, o Uruguai, como podemos observar na Tabela 2, dispõe do segundo melhor índice de Educação dos países do bloco. A Argentina, país com melhor IDH do Mercosul, também é o que apresenta a maior média de qualidade educacional, seguida de Uruguai, Venezuela, Brasil e Paraguai.

Tabela 2: Índice de Educação dos países do Mercosul

\begin{tabular}{lcc}
\hline \multicolumn{1}{c|}{ PAÍSES } & Índice \\
\hline Argentina & 0,826 \\
Brasil & & 0,677 \\
Paraguai & & 0,588 \\
Uruguai & 0,712 \\
Venezuela & 0,691 \\
\hline
\end{tabular}

Fonte: Relatório do Programa das Nações Unidas para o Desenvolvimento (PNUD, 2015).

Se observarmos o quadro evolutivo com relação ao Índice de Educação registrado no Gráfico 2, identificamos que todos os países avançaram. Deve-se destacar que Paraguai e Uruguai apresentaram evoluções bem incipientes, porém, o segundo já era detentor de índice educacional satisfatório em 2005, o que demonstrou uma estagnação, ao passo que o primeiro ainda continua mantendo o posto de menor índice dentre os países do bloco. No outro cenário, Argentina, Venezuela e Brasil destoaram dos demais no crescimento de índice educacional, ainda que seja preciso enfatizar que, especialmente os dois últimos, assinalam inúmeros desafios que impedem o avanço da área.

Gráfico 2: Evolução do índice de Educação dos países do Mercosul (2005 e 2015) 


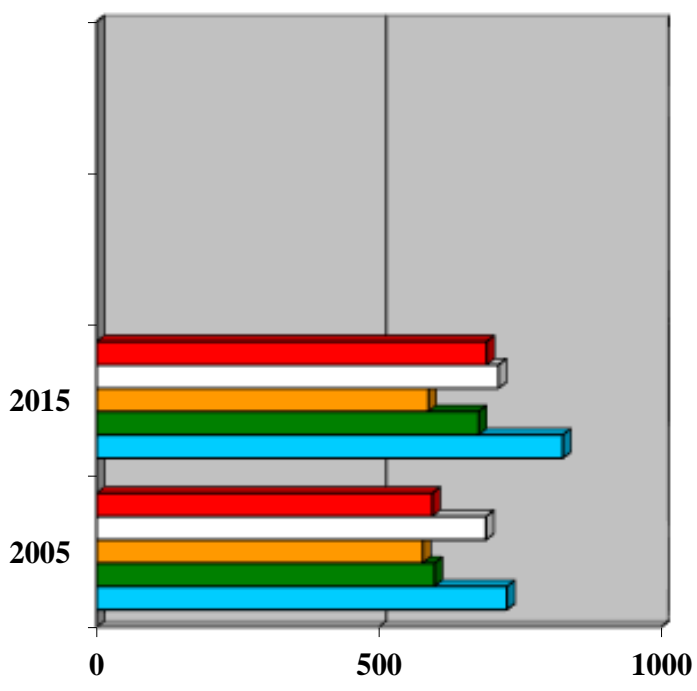

\begin{tabular}{|l|}
$\square$ Venezuela \\
$\square$ Uruguai \\
$\square$ Paraguai \\
$\square$ Brasil \\
$\square$ Argentina \\
\hline
\end{tabular}

Fonte: Elaboração própria a partir dos dados do Relatório do Programa das Nações Unidas para o Desenvolvimento (PNUD, 2005 e 2015).

Se por um lado, o primeiro indicador de qualidade é a cobertura, em termos de oferta, podemos considerar que todos os países do Mercosul ampliaram de um modo geral as matrículas nas suas referidas etapas obrigatórias e gratuitas, em que pese a relação de diminuição da população de determinadas faixas etária e realidade paraguaia quanto à Educação Primária. Por outro lado, o crescimento das oportunidades de escolarização à sociedade desencadeou inúmeros desafios relativos aos países da região, a demanda por expansão de vagas em outras etapas formativas, o prosseguimento dos estudos provocados por altas taxas de repetência e evasão, assim como a necessidade de melhoria da qualidade educacional ofertada.

Akkari e Nogueira (2007, p. 134) apontam que, ao contrário de certas crenças veiculadas pela mídia internacional, a América Latina não é uma região que concentra elevados índices de crianças não escolarizadas, em idade referente às etapas obrigatórias. Na contramão dessa crença, há indicadores que apontam a ampliação do acesso das crianças a instituições de ensino na região. "Um relatório recente da UNESCO de 2001 estima que 32 países não conseguirão enviar todas as suas crianças à escola primária até 2015. Este relatório não atinge a América Latina, que aparentemente apresenta-se capaz de alfabetizar todas as suas crianças".

O questionamento que tem sido pauta das diretrizes internacionais e, até mesmo, de alguns países da região, é a necessidade desse processo de escolarização possuir, também, o alcance qualitativo e não apenas quantitativo. "Um grande número de

RIAEE - Revista Ibero-Americana de Estudos em Educação, Araraquara, v.12, n.4, p.2245-2260, out./dez. 2017. 
crianças está freqüentando as escolas públicas na América Latina, mas estão de fato sendo alfabetizadas? Estão sendo preparadas para o trabalho e para os desafios da vida cotidiana?" (AKKARI; NOGUEIRA, 2007, p. 134).

Oliveira (2007) enfatiza que, paradoxalmente, mais educação gera a demanda por mais educação. A ampliação da oferta de matrículas nos países, somada a quase universalização das etapas obrigatórias, com exceção do Paraguai, passa a desencadear novas demandas populares por acesso à educação. Trata-se, pois, da necessidade de expansão das matrículas nas demais etapas da educação básica dos países, o que está atrelado ao aumento dos recursos para a área, vislumbrando, assim, um processo educacional que faça a cobertura de um maior número de pessoas, por mais tempo e com qualidade.

A Educação Infantil e a Educação Média devem, também, ser consideradas um direito fundamental, obrigatório e gratuito do indivíduo e que, portanto, precisa figurar nos marcos legais dos países. Além disso, o direito é histórico e dinâmico, ou seja, sua institucionalização será direcionada conforme as demandas da sociedade. No panorama apresentado pela realidade mercosulina, evidencia-se que educação gera mais educação. Desse modo, compreendemos que a ampliação da escolarização obrigatória para além da etapa primária constitui-se em uma necessidade histórica dos países Sul-americanos em direção à expansão das possibilidades da formação integral. Isso implica uma defesa da educação enquanto um direito humano e que deve estar na contramão dos "[...] processos de seletividade e exclusão, que caracterizam a educação pública em nossa região e ainda uma oposição a toda e qualquer forma de desigualdade de acesso e de distribuição do conhecimento" (TELLO; MAINARDES, 2014, p. 157).

Os países membros do Mercosul demonstraram, ao longo da última década, o crescimento da oferta de oportunidades escolares. Com isso, possibilitou-se a inclusão de parcelas sociais historicamente excluídas das instituições escolares, mas, ao mesmo tempo, provocou a segmentação no próprio sistema educacional. Assim sendo, houve a expansão das taxas da matrícula, diminuição dos índices de analfabetismo nas populações adultas, elevação na média de anos de escolarização, aumento dos recursos destinados à área (ainda que sejam insuficientes), porém, a democratização via qualidade educacional prefigura como um complexo obstáculo, especialmente se considerarmos que estamos falando de realidades socioeconômicas arraigadas de desigualdade (SOUZA, 2017). 
Nessa direção, Santos, Ourique e Silva (2007) esclarecem que o problema da qualidade deve ser enfrentando conjuntamente ao problema da equidade. Isso significa que não é possível analisar as limitações evidenciadas nos sistemas educacionais dos países sem considerar o nível socioeconômico, assim como as particularidades inerentes às diferenças entre culturas, etnias e raças que são expressas em uma região tão plural como a que envolve o Mercosul. Os vínculos entre educação e sociedade são estreitos e se influenciam mutuamente, dessa forma, não é possível definir políticas públicas para a área sem considerar esses determinantes.

Debater tais questões remete à apreensão de um conjunto de determinantes que interferem, nesse processo, no âmbito das relações sociais mais amplas, envolvendo questões macroestruturais, como concentração de renda, desigualdade social, educação como direito, entre outras. Envolve, igualmente, questões concernentes à análise de sistemas e unidades escolares, bem como ao processo de organização e gestão do trabalho escolar, que implica questões como condições de trabalho, processos de gestão da escola, dinâmica curricular, formação e profissionalização docente. Em outras palavras, é fundamental ressaltar que a educação se articula a diferentes dimensões e espaços da vida social sendo, ela própria, elemento constitutivo e constituinte das relações sociais mais amplas. A educação, portanto, é perpassada pelos limites e possibilidades da dinâmica pedagógica, econômica, social, cultural e política de uma dada sociedade. (DOURADO; OLIVEIRA, 2009, p. 202)

Embora, em termos de cobertura dos anos de escolaridade obrigatórios dos países, Souza (2017) aponte uma considerável evolução, os indicadores referentes a qualidade educacional acendem as luzes do alarme sobre a materialização do direito à educação nos países membros do Mercosul. A falta de vagas para as demais etapas formativas da educação básica, a limitação dos recursos e a baixa qualidade ilustram os desafios dos Estados para conseguir a inclusão, no sistema de ensino, daqueles que, atualmente, estão excluídos, seja pelo acesso, pela permanência ou pela insuficiência educacional. Esse cenário imprime ao bloco uma pactuação ruma à definição de ações que busquem superar o quadro imposto, sob pena de retroceder os avanços conquistados até aqui e, consequentemente, comprometer a educação das gerações futuras do povo mercosulino.

É preciso registrar o reconhecimento de que a análise dos indicadores apresentados não é suficiente para compreender a totalidade do fenômeno do direito à educação básica, devido à abrangência e complexidade das particularidades relacionadas às coberturas educacionais dos sistemas de ensino dos países. Contudo,

RIAEE - Revista Ibero-Americana de Estudos em Educação, Araraquara, v.12, n.4, p.2245-2260, out./dez. 2017. 
mesmo com essas limitações, os dados analisados nos permitiram aferir uma leitura sumária da realidade e dos desafios impostos não só à garantia, mas, principalmente, à efetivação do direito educacional no âmbito dos membros do Mercosul.

\section{Considerações finais}

Um dos principais desafios que perpassa o direito à educação nos países do Mercosul consiste na promoção de uma educação de qualidade, haja vista que, na medida em que foram ingressando nas instituições grupos sociais que, historicamente, estiveram excluídos, não ocorreu, nestes países, uma agenda de políticas que propicia uma devida reformulação do sistema de ensino com o intuito de promover um quadro educacional de qualidade.

É crucial ponderar que a prerrogativa do direito à educação de qualidade é dinâmica e distinta, pois vai representar as demandas históricas de cada país. Se de um lado, no que concerne a educação obrigatória, Venezuela e, principalmente o Paraguai ainda enfrentam o desafio da universalização, por outro, Argentina e Uruguai se defrontam com as dificuldades inerentes as taxas de reprovação e evasão. O Brasil, embora tenha, praticamente, universalizado o Ensino Fundamental, terá que prover as condições reais para assistir a recente ampliação dos anos de escolaridade obrigatória.

Nessa vertente, podemos inferir que há um extenso caminho a se percorrer para a efetividade do direito à educação básica entre os membros do Mercosul, no qual haja o provimento do acesso, permanência e qualidade. Especificamente sobre a concepção de qualidade, seria fundamental a criação de um sistema próprio de avaliação da educação básica, que, por sua vez, fosse aplicado em cada país e que fosse convergente com as especificidades da região. A ausência de um instrumento de avaliação induz à fragmentação das políticas educacionais entre os membros do bloco, o que leva ao distanciamento da integração regional e, principalmente, fragiliza a concretização do direito à educação.

Além da necessidade de prover o amplo acesso e permanência de todos à educação básica de qualidade, é necessário mudanças profundas nas estruturas sociais, especialmente porque o atual momento conjuntural econômico dos países do Mercosul demandará não só de políticas educacionais, mas, também, de políticas públicas que propiciem condições de inserção social da população oriunda das classes vulneráveis. Caso contrário, a educação representará um privilégio e não um direito.

RIAEE - Revista Ibero-Americana de Estudos em Educação, Araraquara, v.12, n.4, p.2245-2260, out./dez. 2017. 
É importante salientar que nos últimos anos, vários países do mundo têm enfrentado crises econômicas. No âmbito do Mercosul, essa realidade tem atingido de forma acentuada as suas principais economias (Brasil, Argentina e Venezuela), o que, consequentemente, também afeta Uruguai e Paraguai. Esse quadro ameaça não só a crescente ampliação dos investimentos destinadas à educação observadas em todos países do bloco, mas a evolução das melhorias dos indicadores educacionais, como, também, o que já foi alcançado, o que demanda do bloco, mais do que nunca, o fortalecimento da integração regional e a adoção, em conjunto, de políticas públicas destinadas a reduzir a vulnerabilidade dos seus países membros.

Devido à abrangência do tema, reconhecemos que há um extenso campo de investigação aberto para que se possa aprofundar e produzir conhecimento novo sobre essa temática. Portanto, é imprescindível a realização de estudos que investiguem a efetivação do direito à educação nos países membros do Mercosul, como fenômeno a ser interrogado na perspectiva de uma análise política, sociológica e pedagógica, objetivando avançar na busca de uma efetiva educação de qualidade para todos.

\section{REFERÊNCIAS}

AKKARI, A.; NOGUEIRA, N. As condições para uma educação básica de qualidade na América Latina. Diálogo Educacional, Curitiba, v. 7, n. 22, p. 131-145, 2007.

\section{BABINSKI, D. B. de O. O direito à educação básica no âmbito do Mercosul:} proteção normativa nos planos constitucional, internacional e regional 2010. 182f. Dissertação (Mestrado em Direito) - Faculdade de Direito, Universidade de São Paulo, São Paulo, 2010.

CABRAL, K. M.; DI GIORGI, C. A. G. O direito à qualidade da Educação Básica no Brasil: uma análise da legislação pertinente e das definições pedagógicas necessárias para uma demanda judicial. Educação, Porto Alegre, v. 35, n. 1, p. 116-128, 2012.

DOURADO, L. F.; OLIVEIRA, J. F. A qualidade da educação: perspectivas e desafios. Cadernos Cedes, Campinas, 29, n. 78, p. 201-215, 2009.

MINAYO, M. C. de S. Construção de indicadores qualitativos para avaliação de mudanças. Revista Brasileira de Educação Médica, Rio de Janeiro, n. 33, p. 83-91, 2009.

OLIVEIRA, R. P. Da universalização do Ensino Fundamental ao desafio da qualidade: uma análise histórica. Educação e Sociedade, Campinas, v. 28, n. 100, p. 661-690, 2007. 
OLIVEIRA, R. P.; ARAÚJO, G. C. Qualidade do ensino: uma nova dimensão da luta pelo direito à educação. Revista Brasileira de Educação, Rio de Janeiro, n. 28, p. 5 24, 2005.

PILETTI, N.; PRAXEDES, W. Mercosul, competitividade e educação. Estudos Avançados, São Paulo, v. 12 n. 34, p. 219-233, 1998.

PROGRAMA DAS NAÇÕES UNIDAS PARA O DESENVOLVIMENTO - PNUD. Relatório de desenvolvimento humano 2005: cooperação internacional em um encruzilhada. Lisboa: Instituto Camões, 2005.

PROGRAMA DAS NAÇÕES UNIDAS PARA O DESENVOLVIMENTO - PNUD. Relatório de desenvolvimento humano 2015: o trabalho como motor de desenvolvimento humano. Lisboa: Instituto Camões, 2015.

SANTOS, A. L. F.; AZEVEDO, J. M. L. A pós-graduação no Brasil, a pesquisa em educação e os estudos sobre a política educacional: os contornos da constituição de um campo acadêmico. Revista Brasileira de Educação, Rio de Janeiro, v. 14, n. 42, p. 534- 550, 2009.

SANTOS, G. B. dos.; OURIQUE, S. A.; SILVA, W. A qualidade da educação na América Latina. Revista da Faced, Salvador, n.12, p.33-49, 2007.

SILVEIRA, Z. C. Setor educacional do Mercosul: convergência e integração regional da educação superior brasileira. Avaliação, Campinas; v. 21, n. 3, p. 901 - 927, 2016.

SOUZA, K. R. Direito à educação nos países membros do Mercosul: um estudo comparado. 2017. 346f. Tese (Doutorado em Educação Escolar) - Universidade Estadual Paulista, Araraquara-SP, 2017.

SUSMEL, N. Escenarios y desafios de la educación preescolar, básica y media en Argentina. In: SPOLA. Los desafios de educación preescolar, básica y media em América Latina. Mexico: Konrad-Adenauer, 2014. p. 13 - 38.

TELLO, C.; MAINARDES, J. A educação secundária na América Latina como um direito democrático e universal: uma análise de documentos do Banco Mundial e do Banco Interamericano de Desenvolvimento. Educação e Filosofia, Uberlândia, v. 28, p. 155-179, 2014.

UNESCO. Situación Educativa de América Latina y el Caribe. Santiago: Ediciones del Imbunche, 2013.

VIEIRA, F. S. C. Direito fundamental à educação pública de qualidade: legislação pertinente e sua efetiva aplicabilidade. In: REUNIÃO ASSOCIAÇÃO NACIONAL DE PÓS- GRADUAÇÃO E PESQUISA EM EDUCAÇÃO - SUL, 10², Florianopólis. Anais... Florianópolis: 2014. 


\section{Como citar este artigo:}

SOUZA, Kellcia Rezende.; KERBAUY, Maria Teresa Miceli. O direito à educação de qualidade no Mercosul. Revista Ibero-Americana de Estudos em Educação, Araraquara, v. 12, n. 4, p. 2245-2260, out./dez. 2017. Disponível em: <http://dx.doi.org/10.21723/riaee.v12.n4.out./dez.2017.10771>. E-ISSN: 1982-5587.

Submetido em: 10/02/2017

Aprovado em: 18/06/2017 